\title{
Reflex Influence of Selective Coronary Artery Occlusion on the Total Capacitance Vasculature in the Dog
}

David L. Rutlen and Reed S. Underwood

Cardiology Section, Department of Internal Medicine, Yale

University School of Medicine, New Haven, Connecticut 06510

bstract. While the reflex influence of selective coronary arterial occlusion on the resistance vasculature has been well delineated, the reflex influence of coronary occlusion on the total capacitance vasculature has not been examined. Thus, selective coronary occlusions were performed in 65 anesthetized dogs. Blood was drained from the vena cavae and returned to the right atrium at a constant rate so that changes in total intravascular volume could be recorded as reciprocal changes in extracorporeal reservoir volume. In 10 animals, $2.5 \mathrm{~min}$ of left anterior descending occlusion was associated with only an insignificant total volume increase of $6 \pm 4 \mathrm{ml}$ (SEM), whereas $2.5 \mathrm{~min}$ of left circumflex occlusion was associated with a $27 \pm 4 \mathrm{ml}(P<0.001)$ increase in volume, which was significantly attenuated $(P<0.001)$ to only a $7 \pm 3 \mathrm{ml}$ increase after cervical vagectomy. Epicardial lidocaine in four animals reduced the volume increment associated with circumflex occlusion from $30 \pm 3$ to $11 \pm 4$ $\mathrm{ml}(P<0.025)$. The volume increase was attenuated from $45 \pm 6$ to $24 \pm 5 \mathrm{ml}$ with propranolol administration $(P$ $<0.001$ ) (seven animals) and from $26 \pm 5$ to $17 \pm 6 \mathrm{ml}$ with atropine $(P<0.025)$ (eight animals), but was not attenuated with phenoxybenzamine $(28 \pm 7 \mathrm{ml}$ before and $25 \pm 2$ $\mathrm{ml}$ after phenoxybenzamine) (five animals). Double blockade with propranolol and atropine reduced the volume increase to $3 \pm 2 \mathrm{ml}$ (NS) in four of these animals. In order to compare the influences of selective beta- 1 adrenergic blockade and combined beta- 1 and beta- 2 blockade, volume responses were assessed before and after

This work was presented in part at the 1980 National Meeting of the American Federation for Clinical Research (Clin Res. 28:207A).

Dr. Rutlen is the Duberg Scholar in Cardiovascular Disease. Address correspondence to Dr. Rutlen. 1983.

Received for publication 6 June 1983 and in revised form 30 September

J. Clin. Invest.

(C) The American Society for Clinical Investigation, Inc.

$0021-9738 / 84 / 01 / 0241 / 10 \quad \$ 1.00$

Volume 73, January 1984, 241-250 administration of metoprolol or propranolol in doses that produced the same amount of beta-1 blockade (15 animals). The volume increase associated with circumflex occlusion was not attenuated after beta- 1 blockade $(20 \pm 4$ $\mathrm{ml}$ before and $18 \pm 5 \mathrm{ml}$ after metoprolol) (eight animals) but was attenuated from $30 \pm 5$ to $14 \pm 5 \mathrm{ml}$ after propranolol $(P<0.05)$ (seven animals). To examine further the efferent limb of the observed reflex, circumflex occlusions were performed before and after either vagectomy at the level of the diaphragm or section of the sympathetic splanchnic nerves in 12 animals. The volume increment was significantly attenuated after either procedure. In four animals undergoing prior arterial baroreceptor denervation, volume still increased $30 \pm 6 \mathrm{ml}(P<0.001)$ with circumflex occlusion. Thus, inferior myocardial ischemia is associated with an autonomic reflex that acts to increase total intravascular volume. The afferent limb is mediated through the vagi, and the efferent limb, through changes in peripheral beta adrenergic and parasympathetic receptor stimulation.

\section{Introduction}

It is well recognized that patients with inferior wall myocardial infarction are more likely to manifest bradycardia and hypotension than patients with anterior wall myocardial infarction (1-4). Work by several investigators suggests a mechanism that might contribute to the hypotension. The work has demonstrated that coronary occlusion is associated with an autonomic reflex that acts to decrease peripheral arterial resistance (5-9). Further studies suggest that this reflex is localized to stimulation of intracardiac receptors in the inferior wall of the heart (10).

It is possible that the hypotension associated with inferior wall myocardial infarction is mediated also by an increase in blood volume in the peripheral capacitance vasculature and subsequent decreases in venous return and cardiac output. However, whether coronary occlusion is associated with a change in total capacitance blood volume has not been examined. Thus, the present study was undertaken to examine the influence of selective inferior and anterior wall myocardial ischemia on total intravascular volume in the capacitance vasculature. A venous 
bypass preparation was used to quantitate total intravascular volume changes and to determine the extent by which these changes were mediated through the autonomic nervous system. Furthermore, the afferent and efferent limbs of the observed reflex were delineated.

\section{Methods}

65 mongrel dogs of either sex were studied. The dogs weighed between 10.5 and $24.5 \mathrm{~kg}$ (mean $14.4 \pm 0.3 \mathrm{~kg}$ ) with only five of the animals weighing $>16.8 \mathrm{~kg}$. The dogs were anesthetized with chloralose (60-80 $\mathrm{mg} / \mathrm{kg}$ i.v.) and urethan $(600-800 \mathrm{mg} / \mathrm{kg}$ i.v.), intubated, and ventilated with a mixture of room air and $100 \%$ oxygen. In each animal, a median sternotomy was performed, and 3,000 $\mathrm{U}$ of sodium heparin were administered intravenously. The azygos vein was ligated, and while taking special care to avoid injury to the thoracic vagi, the superior and inferior vena cavae were cannulated with 32 or 34 French catheters (Fig. 1). The total systemic venous return was drained into a Q-120 cardiotomy reservoir (Bentley Laboratories Inc., Irvine, CA). By adjusting the height of the venous drainage tubing, central venous pressure was set at $5 \mathrm{~cm}$ $\mathrm{H}_{2} \mathrm{O}$ at the beginning of each experiment. From the cardiotomy reservoir, blood was pumped (Travenol perfusion pump, Baxter Travenol Laboratories, Morton Grove, IL) into a 2-liter graduated cylinder. The pump was maintained at a constant rate which was sufficiently rapid to prevent accumulation of blood in the cardiotomy reservoir. From the 2-liter graduated cylinder, blood was returned to the right atrium via a 26 French catheter in the right atrial appendage. Blood was returned to the animal at a constant rate, and thus, it was possible to record changes in total intravascular volume in each animal as reciprocal changes in volume in the graduated cylinder. Brachial artery, left atrial, and central venous pressures and pressure at the bottom of the graduated cylinder were measured with P23Db pressure transducers (Gould Inc., Instruments

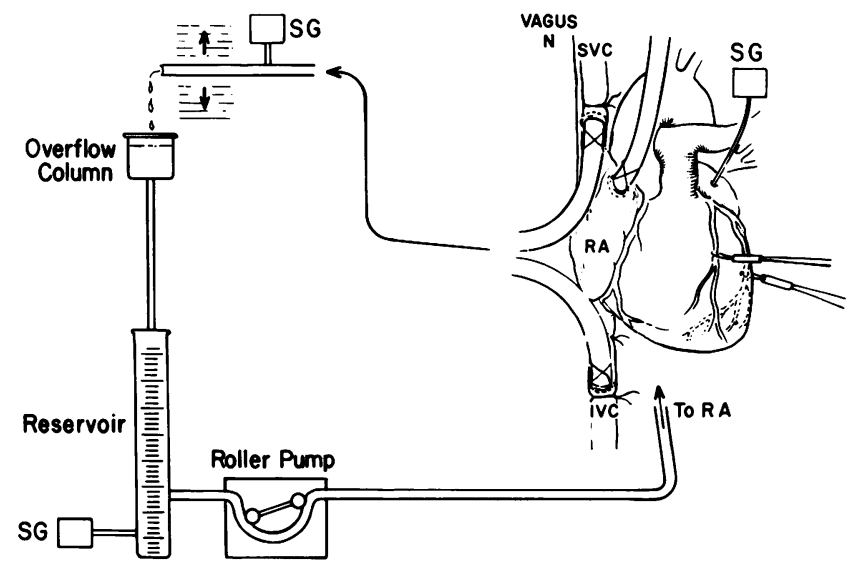

Figure 1. Experimental preparation. Blood was drained from the vena cavae and returned to the right atrium at a constant rate so that changes in the dog's total intravascular volume could be recorded as reciprocal changes in extracorporeal reservoir volume. Snare occluders were placed around midsections of the left anterior descending and left circumflex arteries. See text for details. SG, strain gauge; N, nerve; SVC, superior vena cava; IVC, inferior vena cava; RA, right atrium.
Div., Cleveland, $\mathrm{OH}$ ). The transducer that recorded pressure in the graduated cylinder was calibrated by adding known volumes of blood to the cylinder at the beginning of each experiment. All pressures and the electrocardiogram were recorded continuously with an 8 channel 7758A Hewlett Packard recorder (Medical Instruments Div., Waltham, MA). Arterial $\mathrm{O}_{2}$ and $\mathrm{CO}_{2}$ tensions and $\mathrm{pH}$ were determined frequently throughout the course of each experiment with a Micro $13 \mathrm{pH} / \mathrm{blood}$ gas analyzer (Instrumentation Laboratory Inc., Lexington, MA). The appearance of a corneal reflex or spontaneous respirations prompted the additional administration of $20-50 \mathrm{mg} / \mathrm{kg}$ chloralose and $200-500$ $\mathrm{mg} / \mathrm{kg}$ urethan in 6 of the 65 animals. Blood loss due to the surgery was estimated to be $30-40 \mathrm{ml}$ during the initial preparation of the animals and $\sim 10 \mathrm{ml} / \mathrm{h}$ thereafter.

Midsections of the left circumflex (LCX) ${ }^{1}$ and left anterior descending (LAD) coronary arteries or the LCX coronary alone were dissected from the epicardium. Suture material was placed around each midsection, and a piece of polyethylene tubing was slipped over the suture material, thereby allowing intermittent occlusion of each coronary artery by firmly securing the tubing against the vessel. At the end of an experiment, the heart was removed and each coronary was cannulated with $0.061 \mathrm{~cm}$ o.d. polyethylene tubing at the point of occlusion. The circumflex and anterior descending arteries were perfused with yellow and blue Latex (Ward's Natural Science Establishment, Inc., Rochester, NY), respectively, at a perfusion pressure of $120 \mathrm{mmHg}$ for $1 \mathrm{~h}$. After the atria were removed, the two regions of myocardium, which were supplied by each coronary (already injected with a particular color), were removed and separately weighed.

In each of 10 dogs, the LCX and LAD were separately occluded twice each in alternating order for 2.5 -min periods. In five of the dogs, the LCX was occluded first, and in the other five, the LAD was occluded first. All pressures and volumes were recorded for at least $3 \mathrm{~min}$ before and after each period of coronary occlusion. Bilateral cervical vagectomies were then performed in each of the 10 animals, and LCX and LAD occlusions were repeated twice each in the same order as had been performed before vagectomies.

The influence of epicardial lidocaine administration on the volume response associated with LCX occlusion was examined in four other animals. LCX occlusion was performed for $2.5 \mathrm{~min}$ as previously described. $10 \mathrm{ml}$ of $1 \%$ lidocaine hydrochloride (Xylocaine, Astra Pharmaceutical Products, Inc., Worcester, MA) was then applied directly to the epicardium, and the same concentration of lidocaine solution was dripped over the epicardial surface at a rate of $2 \mathrm{ml} / \mathrm{min}$. LCX occlusion was repeated for $2.5 \mathrm{~min}$ in the presence of lidocaine. In two of the four animals, the lidocaine drip was discontinued and the lidocaine was flushed from the epicardial surface with $200 \mathrm{ml}$ of normal saline solution. LCX occlusions were again repeated in the absence and presence of lidocaine in these two animals.

The influence of selective autonomic blockade was assessed in an additional 20 animals. LCX occlusion was performed for $2.5 \mathrm{~min}$ before and after alpha adrenergic blockade with $100-150 \mathrm{mg}$ i.v. phenoxybenzamine hydrochloride (Dibenzyline; supplied by SmithKline Corp., Philadelphia, PA) (five animals), before and after beta adrenergic receptor blockade with 9-57 mg i.v. propranolol hydrochloride (Inderal; supplied by Ayerst Laboratories, New York, NY) (seven animals), and before and after cholinergic receptor blockade with $8-15 \mathrm{mg}$ atropine sulfate

1. Abbreviations used in this paper: LAD, left anterior descending; LCX, left circumflex. 
(Eli Lilly and Company, Indianapolis, IN) (eight animals). In four of the eight animals that received atropine sulfate, LCX occlusion was performed again after the administration of 5-17 mg propranolol hydrochloride. The adequacy of selective or combined receptor blockade was tested before and after blockade by noting blood pressure and heart rate responses to left atrial administration of $30 \mu \mathrm{g}$ norepinephrine bitartrate (levophed; Breon Laboratories, Inc., New York, NY), $12 \mu \mathrm{g}$ isoproterenol hydrochloride (Isuprel; Breon Laboratories, Inc.), and 10 $\mu \mathrm{g}$ acetylcholine chloride (Sigma Chemical Co., St. Louis, MO), respectively. The adequacy of blockade was confirmed by noting the absence of heart rate or pressure responses to the left atrial injection of these agents before and after each period of LCX occlusion performed in the presence of selective or combined receptor blockade.

To compare the influences of selective beta-1 adrenergic receptor blockade and combined beta- 1 and beta- 2 blockade, LCX occlusion was performed for $2.5 \mathrm{~min}$ in another 15 animals before and after beta1 blockade with $6 \mathrm{mg}$ metoprolol tartrate (Lopressor; supplied by CibaGeigy Corp., Pharmaceuticals Div., Summit, NJ) (eight animals) and before and after beta-1 and beta- 2 blockade with $5 \mathrm{mg}$ propranolol (seven animals). These doses were selected so that the same amount of beta- 1 blockade was achieved with each drug, as measured by the attenuation of the heart rate response to left atrial administration of 12 $\mu \mathrm{g}$ isoproterenol. Hematocrits were determined at the beginning and completion of the studies in these 15 animals.

Whether release and circulation of a humoral substance influenced the reflex capacitance volume response was examined in 11 of these 15 animals. At the start of the experiment, the entire venous return was diverted to another 2-liter graduated cyclinder and accumulated in that cylinder for $2.5 \mathrm{~min}$. After the blood was emptied back into the first graduated cylinder, LCX occlusion and diversion to the second cylinder were performed simultaneously for $2.5 \mathrm{~min}$. After the blood was again emptied back into the first graduated cylinder, the venous return was again diverted to the second cylinder for $2.5 \mathrm{~min}$. This series of interventions was performed 16 times in the 11 animals. The volume diverted during occlusion was subtracted from the mean of the volumes diverted before and after occlusion in order to ascertain the change in intravascular volume during LCX occlusion in each animal.

The possible contribution of release and circulation of a humoral substance was examined further in another 12 animals. LCX occlusions were performed before and after either vagectomy at a level just above the diaphragm (six animals) or after bilateral section of the thoracic sympathetic (greater) splanchnic nerves (six animals). The latter nerves were sectioned by ablating all nerves in the vicinity of the thirteenth thoracic ganglia of the sympathetic trunks.

To examine whether carotid sinus or aortic baroreceptor stimulation influenced the reflex capacitance volume response, LCX occlusions were performed in four other dogs that had undergone prior carotid sinus or combined carotid sinus and aortic baroreceptor denervation. In all four dogs, carotid sinus baroreceptor denervation was accomplished at the beginning of each study by transecting all nerves in the vicinity of the carotid bifurcation bilaterally. Adequate carotid sinus denervation was confirmed by demonstrating the absence of heart rate and arterial pressure increases with occlusion of each carotid artery. Aortic baroreceptor denervation was also performed in three of the dogs by stripping the adventia from the aorta between the aortic valve and left subclavian artery. The adequacy of aortic denervation was tested before and after stripping the adventia by noting heart rate responses to intraatrial administration of $30 \mu \mathrm{g}$ phenylephrine hydrochloride (Neo-Synephrine; Winthrop Laboratories, New York, NY). Aortic denervation was con- firmed by noting a significant attenuation of the reflex heart rate decrease associated with phenylephrine administration. LCX occlusions were then performed on two occasions before and two occasions after bilateral cervical vagectomies in three of the animals and on one occasion before and one occasion after vagectomies in the other animal.

Control data and data obtained just before the termination of coronary occlusion were averaged separately and expressed as means \pm SEM. Paired $t$ tests were used to assess the statistical significance of hemodynamic changes associated with coronary occlusion. Paired $t$ tests also were used to compare changes obtained under different physiologic or pharmacologic conditions. Statistical significance was assumed at $P<0.05$. The relationship between dog weight and the volume response associated with the initial LCX occlusion was examined by linear regression.

\section{Results}

Hemodynamic values associated with 202.5 -min periods of selective LCX and LAD occlusion in 10 animals are presented in Fig. 2. With LCX occlusion, total intravascular volume increased $27 \pm 4 \mathrm{ml}$ (SEM) $(P<0.001)$, while mean brachial artery pressure decreased from $56 \pm 4$ to $52 \pm 3 \mathrm{mmHg}(P<0.001)$ and mean left atrial pressure increased slightly from $3 \pm 1$ to $4 \pm 1$ $\mathrm{mmHg}(P<0.025)$. With LAD occlusion, total intravascular volume increased by only a small, insignificant amount $(6 \pm 4$ $\mathrm{ml}$ ), while mean brachial arterial pressure decreased slightly from $58 \pm 4$ to $56 \pm 4 \mathrm{mmHg}(P<0.005)$ and mean left atrial pressure increased slightly from $3 \pm 1$ to $4 \pm 1 \mathrm{mmHg}(P<0.01)$.

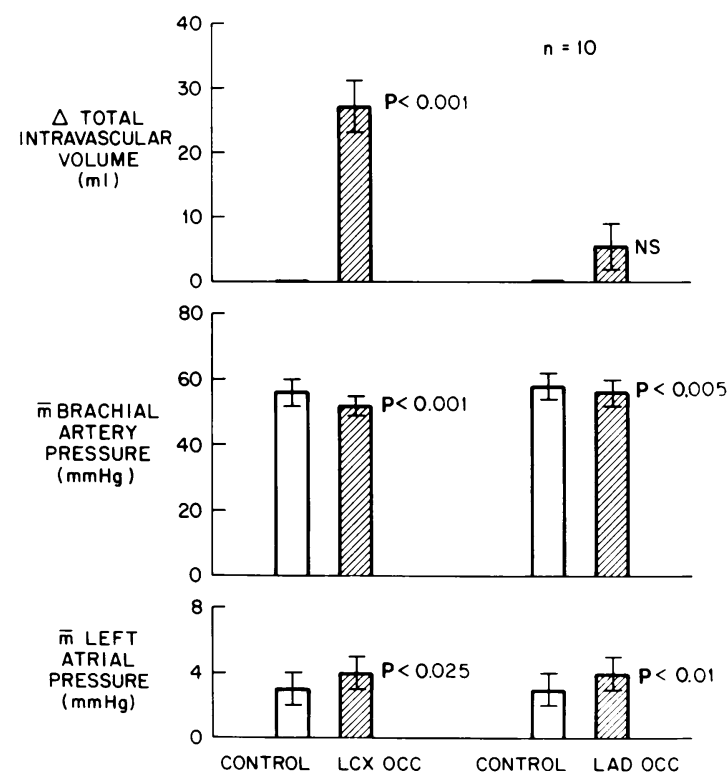

Figure 2. Influence of selective coronary artery occlusion in 10 dogs. Note the significant increase in total intravascular volume with left circumflex coronary occlusion (LCX OCC) and the absence of a significant change in intravascular volume with left anterior descending coronary occlusion (LAD OCC). Each bar represents \pm 1 SEM. NS, not significant. 


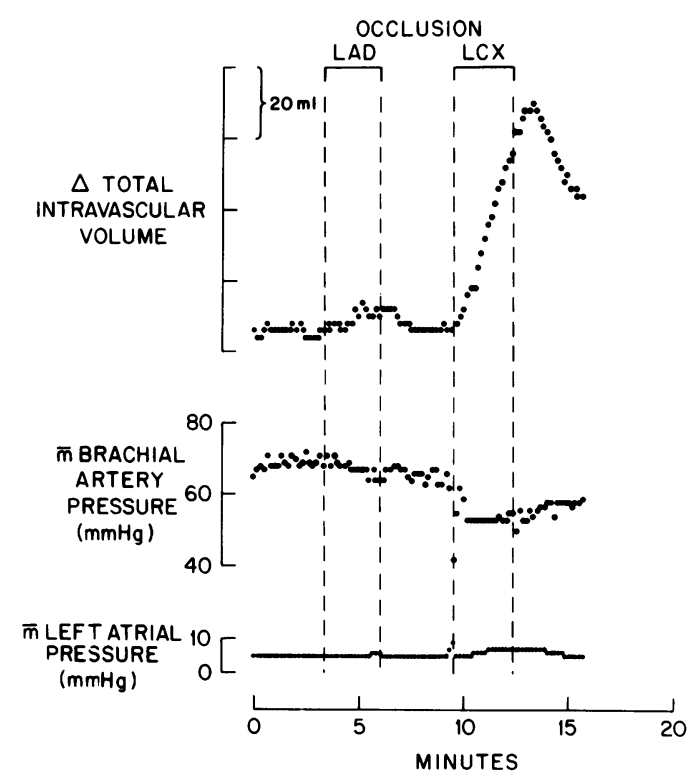

Figure 3. Data obtained during selective coronary artery occlusion in one dog. Note the prompt and substantial volume increase with left circumflex occlusion, the continuing increase in volume at the time of release of the occlusion, and the eventual return of volume towards control after the occlusion had been released. Abbreviations are as in Fig. 2.

Data obtained from one animal are seen in Fig. 3. Note the relatively large increase in intravascular volume during LCX occlusion, the continuing increase in volume at the termination of the LCX occlusion, and the eventual return of volume towards control after release of the LCX occlusion.

Tachyphylaxis does not attenuate the intravascular volume increment with LCX occlusion, since volume increased $26 \pm 4$ $\mathrm{ml}$ with initial LCX occlusion and $29 \pm 4 \mathrm{ml}$ with subsequent LCX occlusion before vagectomy. These changes were not significantly different from each other. Volume increased $3 \pm 2 \mathrm{ml}$ with initial LAD occlusion and $11 \pm 4 \mathrm{ml}$ with subsequent $\mathrm{LAD}$ occlusion before vagectomy. These changes also were not significantly different from each other. The weights of the myocardial regions perfused by the LCX and LAD from their points of occlusion were not significantly different: $19 \pm 2 \mathrm{~g}$ for the LCX and $21 \pm 4 \mathrm{~g}$ for the LAD.

Data obtained with selective coronary occlusion before and after bilateral cervical vagectomies are presented in Figs. 4 and 5. While intravascular volume increased $27 \pm 4 \mathrm{ml}(P<0.001)$ with LCX occlusion before vagectomy, it increased only $7 \pm 3$ $\mathrm{ml}(P<0.025)$ with LCX occlusion after vagectomy (Fig. 4). These responses were significantly different from each other $(P$ $<0.001)$. The decrease in arterial pressure before vagectomy was abolished after vagectomy. Left atrial pressure increased by the same amount before vagectomy as after vagectomy. With LAD occlusion, the small volume increment before vagectomy

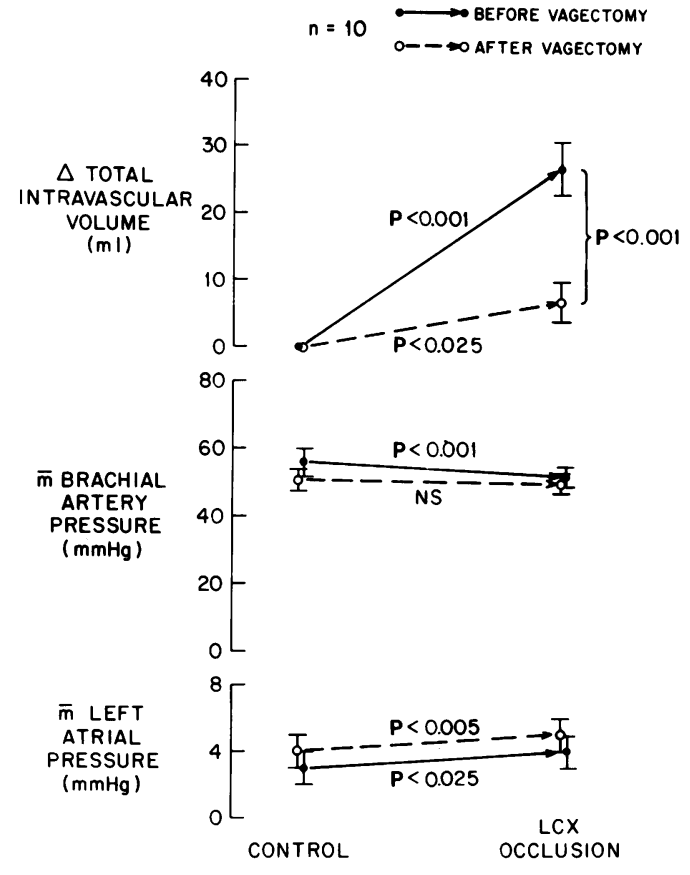

Figure 4. Effect of left circumflex coronary occlusion before and after bilateral cervical vagectomy. The occlusion-associated increase in intravascular volume was virtually abolished by vagectomy. Abbreviations and symbols are the same as in Fig. 2.

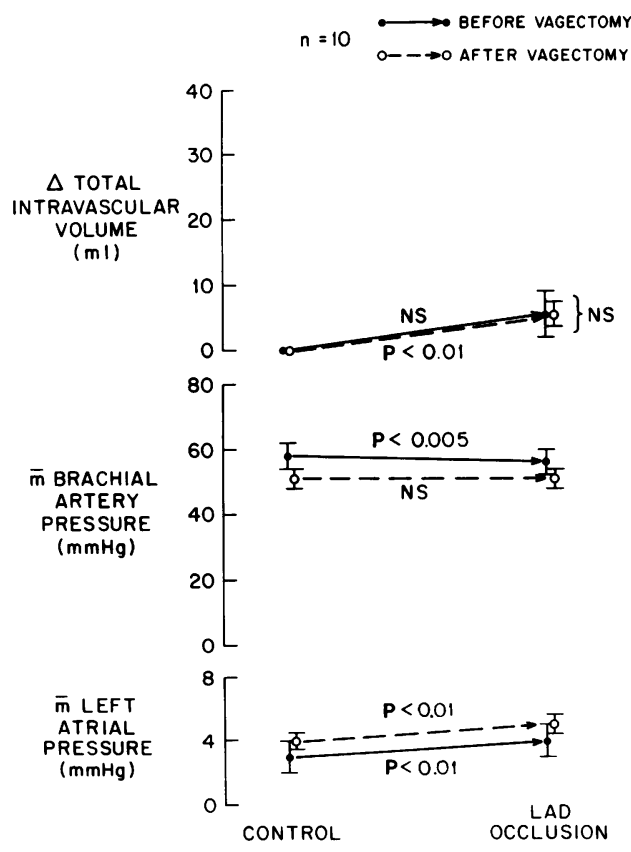

Figure 5. Effect of left anterior descending coronary occlusion before and after bilateral cervical vagectomy. The small occlusion-associated increases in intravascular volume were no different before and after vagectomy. Abbreviations and symbols are the same as in Fig. 2. 
was unchanged after vagectomy (Fig. 5). The small decrease in arterial pressure with LAD occlusion before vagectomy was abolished after vagectomy. Left atrial pressure again increased by the same amount before vagectomy as after vagectomy.

In the four animals in which LCX occlusion was performed on six occasions before and during epicardial lidocaine infusion, intravascular volume increased $30 \pm 3 \mathrm{ml}(P<0.001)$ before lidocaine administration and $11 \pm 4 \mathrm{ml}(P<0.025)$ after lidocaine. These changes were significantly different from each other $(P<0.025)$.

Data obtained before and after adrenergic or cholinergic receptor blockade are presented in Figs. 6-9. In the five animals in which the influence of alpha adrenergic receptor blockade was studied, intravascular volume increased $28 \pm 7 \mathrm{ml}(P<0.01)$ with LCX occlusion before phenoxybenzamine administration and $25 \pm 2 \mathrm{ml}(P<0.001)$ after phenoxybenzamine (Fig. 6). These volume increments were not significantly different from each other. In the seven animals in which the effect of beta adrenergic blockade was studied, volume increased $45 \pm 6 \mathrm{ml}(P$ $<0.001)$ before propranolol administration but only $24 \pm 5 \mathrm{ml}$ $(P<0.005)$ after propranolol (Fig. 7). These increments were significantly different from each other $(P<0.01)$. In the eight animals in which the influence of cholinergic receptor blockade was assessed, intravascular volume increased $26 \pm 5 \mathrm{ml}(P$ $<0.001)$ before atropine administration but only $17 \pm 6 \mathrm{ml}(P$

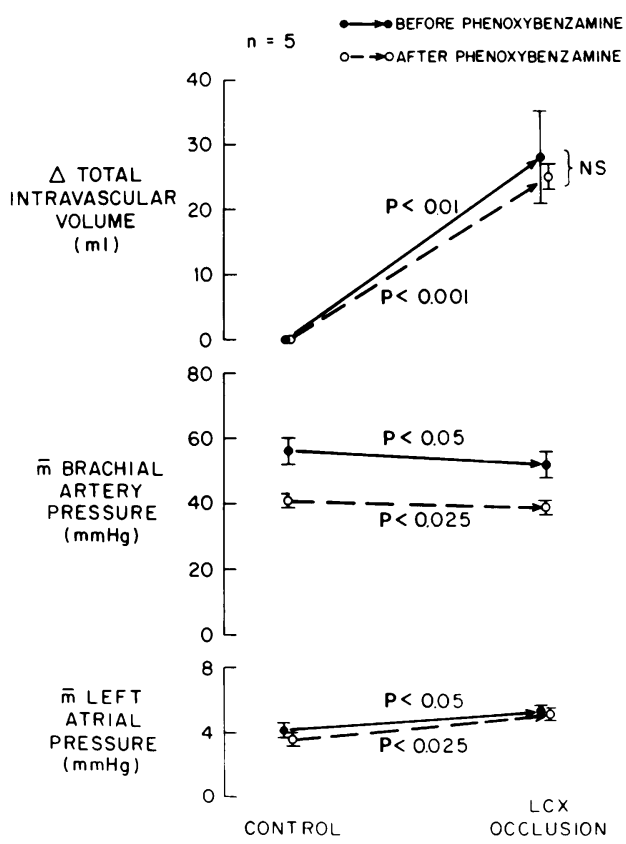

Figure 6. Influence of left circumflex coronary occlusion before and after alpha adrenergic receptor blockade with phenoxybenzamine. Alpha adrenergic blockade did not alter the increase in total intravascular volume associated with circumflex occlusion. Abbreviations and symbols are the same as in Fig. 2.

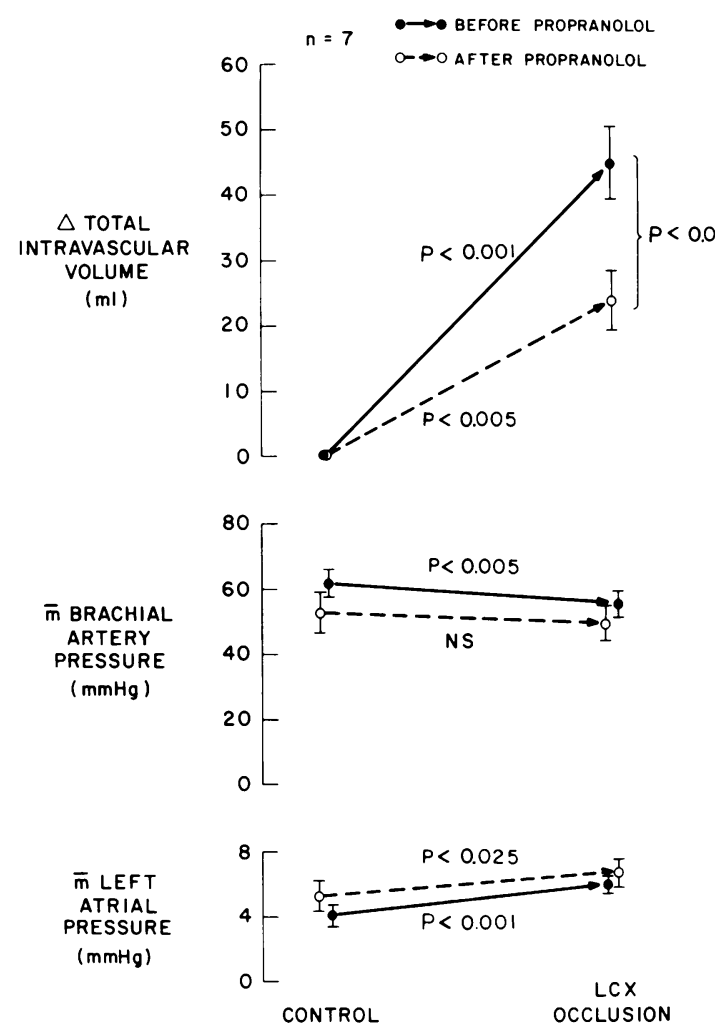

Figure 7. Influence of left circumflex coronary occlusion before and after beta adrenergic receptor blockade with propranolol. Beta adrenergic blockade attenuated but did not abolish the increase in total intravascular volume associated with circumflex occlusion. Abbreviations and symbols are the same as in Fig. 2.

$<0.025$ ) after atropine administration (Fig. 8). These increases were also significantly different from each other $(P<0.025)$. In the four of these eight animals that subsequently underwent combined cholinergic and beta adrenergic receptor blockade, intravascular volume increased $27 \pm 8 \mathrm{ml}(P<0.025)$ with LCX occlusion before atropine and propranolol administration but only an insignificant amount $(3 \pm 2 \mathrm{ml})$ after atropine and propranolol administration (Fig. 9). Intravascular volume increased 94 and $135 \mathrm{ml}$ with phenoxybenzamine administration in the two animals in which volume changes were recorded during alpha adrenergic receptor blockade. Volume increased 2 and $49 \mathrm{ml}$ and decreased 4 and $81 \mathrm{ml}$ with atropine administration in the four animals in which volume changes were recorded during cholinergic blockade.

In the eight animals in which intravascular volume increased $20 \pm 4 \mathrm{ml}(P<0.001)$ with LCX occlusion before beta- 1 adrenergic blockade with $6 \mathrm{mg}$ metoprolol, intravascular volume increased $18 \pm 5 \mathrm{ml}(P<0.01)$ with occlusion after metoprolol. These changes were not significantly different from each other. In seven animals in which intravascular volume increased $30 \pm 5$ $\mathrm{ml}(P<0.001)$ with LCX occlusion before combined beta- 1 


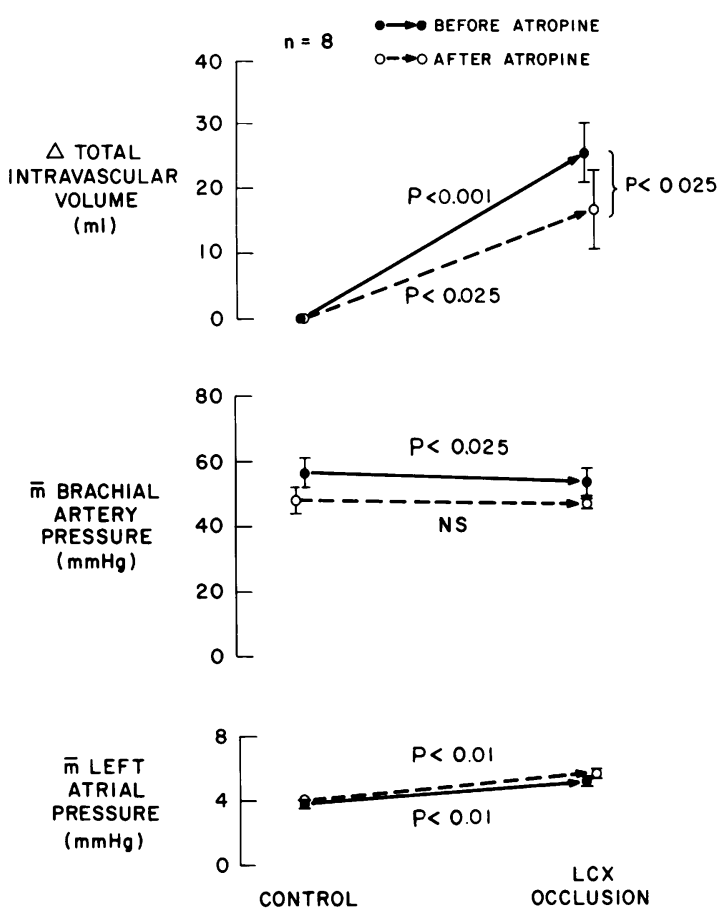

Figure 8. Influence of left circumflex coronary occlusion before and after cholinergic receptor blockade with atropine. Cholinergic blockade attenuated but did not abolish the increase in total intravascular volume associated with circumflex occlusion. Abbreviations and symbols are the same as in Fig. 2.

and beta- 2 blockade with $5 \mathrm{mg}$ propranolol, intravascular volume increased only $14 \pm 5 \mathrm{ml}(P<0.025)$ after propranolol. These changes were significantly different from each other $(P<0.05)$. Metoprolol administration was associated with a $38 \pm 13 \mathrm{ml}(P$ $<0.025$ ) increase in resting intravascular volume and propranolol was associated with a $70 \pm 19 \mathrm{ml}(P<0.01)$ increase in volume in these animals. In the eight animals undergoing blockade with $6 \mathrm{mg}$ metoprolol, heart rate increased from $128 \pm 5$ to $171 \pm 5$ beats $/ \mathrm{min}(P<0.001)$ with isoproterenol before blockade and from $109 \pm 6$ to $114 \pm 4(P=N S)$ with isoproterenol after blockade. In the seven animals undergoing blockade with $5 \mathrm{mg}$ propranolol, heart rate increased from $120 \pm 9$ to $157 \pm 10$ beats/ $\min (P<0.005)$ with isoproterenol before blockade and from $106 \pm 13$ to $110 \pm 5(P=$ NS) with isoproterenol after blockade.

In the 11 of these 15 animals in which the venous return was diverted for 2.5-min periods, LCX occlusion was associated with a $29 \pm 7 \mathrm{ml}(P<0.001)$ increase in intravascular volume during venous diversion. In the 13 of these 15 animals in which the left atria were carefully examined for the presence of left circumflex branches supplying the left atria, small branches distal to the point of LCX occlusion were recognized in six of the animals. No left atrial branches of any size could be recognized distal to the point of occlusion in the other seven animals.
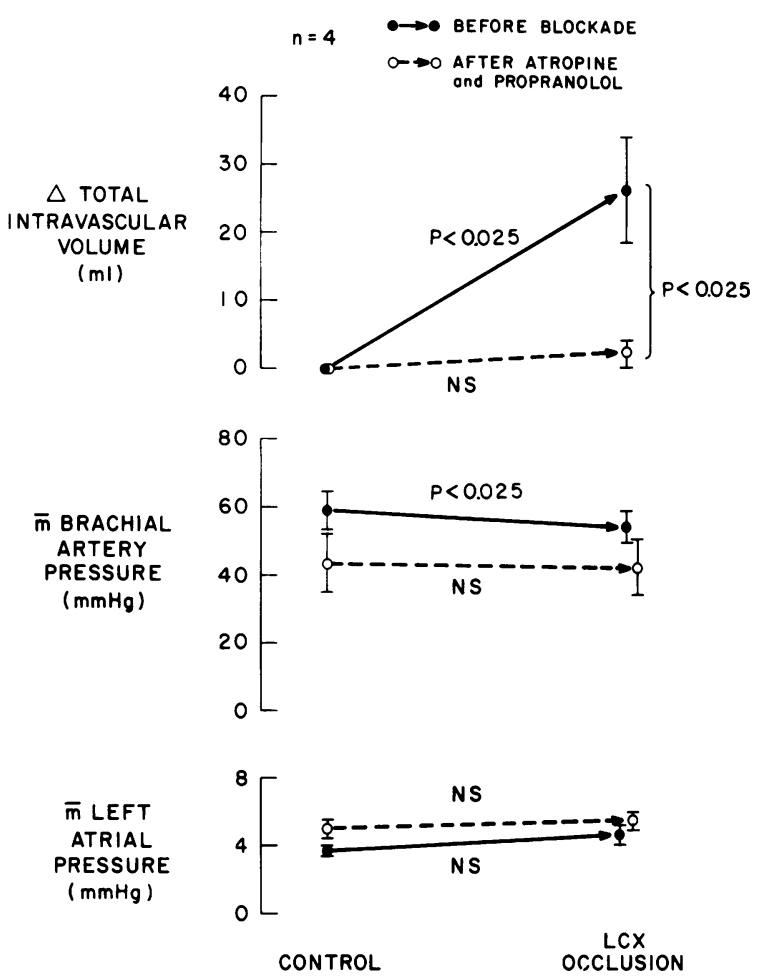

Figure 9. Influence of left circumflex coronary occlusion before and after combined beta adrenergic and cholinergic receptor blockade with propranolol and atropine. Blockade of both types of receptors abolished the increase in total intravascular volume associated with circumflex occlusion. Abbreviations and symbols are the same as in Fig. 2.

For the 12 animals that were examined before and after selective section of efferent nerves, the volume increment associated with LCX occlusion was attenuated from $29 \pm 7$ to $17 \pm 9$ $\mathrm{ml}(P<0.01)$ after vagectomy at the level of the diaphragm (six animals), and from $36 \pm 8$ to $-6 \pm 6 \mathrm{ml}(P<0.01)$ after section of the thoracic sympathetic (greater) splanchnic nerves (six animals).

Fig. 10 illustrates the data associated with LCX occlusion in the four animals that had undergone prior arterial baroreceptor denervation. Since hemodynamic changes associated with coronary occlusion were similar whether carotid sinus denervation alone (one animal) or combined carotid sinus and aortic denervation (three animals) had been performed, data from all four animals were averaged. With LCX occlusion, total intravascular volume increased $30 \pm 6 \mathrm{ml}(P<0.001)$ before vagectomy but only $8 \pm 3 \mathrm{ml}(P<0.01)$ after vagectomy. These changes were significantly different from each other $(P<0.001)$. Arterial pressure decreased from $80 \pm 9$ to $70 \pm 8 \mathrm{mmHg}$ before vagectomy and only from $89 \pm 20$ to $87 \pm 20 \mathrm{mmHg}$ after vagectomy, although neither change was statistically significant. Left atrial pressure increased by the same amount before vagectomy as 


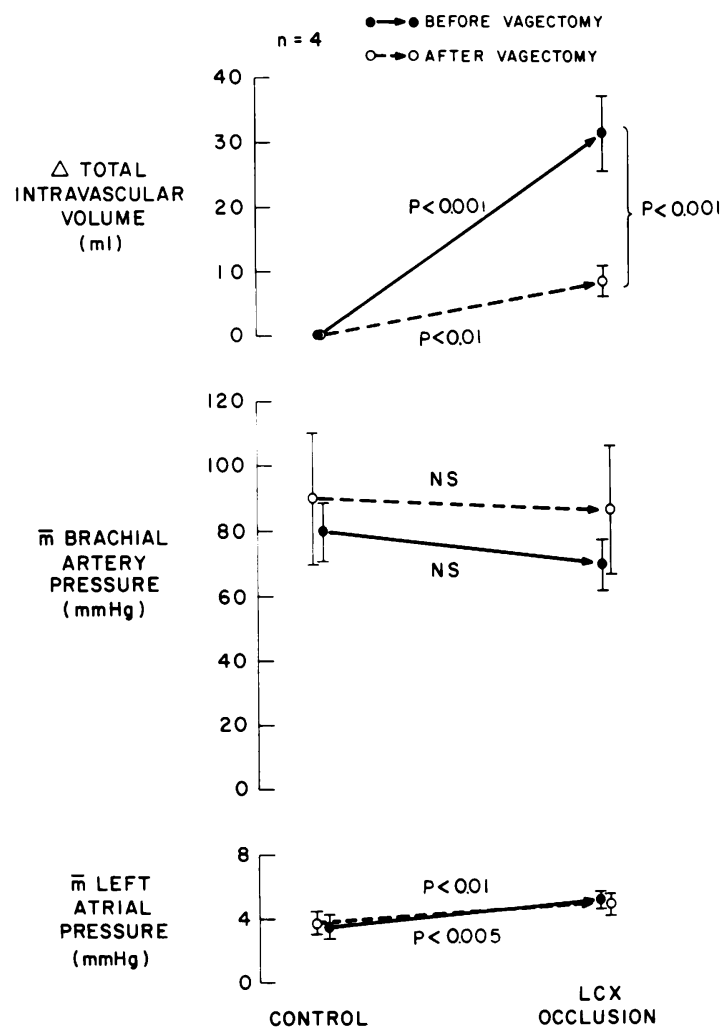

Figure 10. Influence of left circumflex coronary occlusion before and after bilateral cervical vagectomy in animals that had undergone prior arterial baroreceptor denervation. The occlusionassociated increase in intravascular volume was virtually abolished by vagectomy. Note that the volume responses were similar to the responses in animals with intact arterial baroreceptors (Fig. 4). Abbreviations and symbols are the same as in Fig. 2.

after vagectomy. Increases in intravascular volume during initial LCX occlusions did not correlate with the weights of the dogs $(r=0.15)$. In the 15 animals in which hematocrits were determined, hematocrits decreased only slightly from $42 \pm 2$ to $39 \pm 2 \%$ $(P<0.025)$ during the course of the studies.

\section{Discussion}

The data demonstrate that inferior wall myocardial ischemia is associated with a significant increase in total intravascular volume in the capacitance vasculature, while anterior wall ischemia is associated with no significant volume change. The study further demonstrates that the intravascular volume increment with inferior ischemia is accomplished by means of an autonomic reflex mechanism, and the afferent and efferent limbs of the reflex are delineated.

The increase in intravascular volume with LCX occlusion was due almost entirely to an autonomic reflex mechanism, since vagectomy virtually abolished the volume increment. The small occlusion-associated increase in intravascular volume after vagectomy was probably related to the concomitant small increment in left atrial pressure with subsequent passive accumulation of blood volume in the pulmonary vasculature. Intracardiac receptor stimulation initiated the reflex, since the volume increase was markedly attenuated by epicardial lidocaine administration. The reflex volume increment probably was not attenuated by lidocaine administration to the same extent as by vagectomy because of the difficulty in anesthetizing all of the intramural receptors by epicardial application of the agent. At least part, if not all, of the afferent limb of the reflex was mediated through the vagi, since vagectomy virtually abolished the volume increment, while efferent cholinergic blockade with atropine only attenuated the increment. The reflex was likely to be direct and not mediated through the release of humoral agents, since the volume increment was not attenuated when the entire venous return was diverted from the extracorporeal reservoir during circumflex occlusion. Such diversion would prevent recirculation of any humoral agents that might be released. Furthermore, the response was significantly attenuated after selective surgical ablation of efferent parasympathetic or sympathetic nerves. Thus, the intravascular volume increment associated with inferior wall ischemia is accomplished via a directly acting neural reflex. Intracardiac receptor stimulation initiates the reflex and the vagi mediate the afferent limb of the reflex.

The efferent limb of the reflex appeared to be mediated, in part, through changes in beta adrenergic receptor stimulation, since the reflex response was attenuated, but not abolished, after beta adrenergic receptor blockade with propranolol. Two possible objections to this interpretation must be considered. First, one might argue that the attenuation of the response was related to the increase in resting intravascular volume, before occlusion, associated with propranolol administration. However, resting intravascular volume increased by a greater amount after alpha adrenergic blockade with phenoxybenzamine than after beta adrenergic blockade with propranolol, and the reflex volume increment was not attenuated after alpha adrenergic blockade. Secondly, one might argue that blockade of intracardiac beta1 receptors with propranolol caused a decrease in ventricular contractility and a subsequent attenuation of the change in afferent vagal activity with circumflex occlusion. One would argue further that the attenuation of the change in afferent vagal activity resulted in an attenuation of the reflex volume increment. Such an argument is supported by recordings by Thames (11) of the discharge frequency of afferent vagal fibers innervating the left ventricle. He noted that propranolol administration attenuates the increase in discharge frequency associated with graded occlusion of the ascending aorta. The attenuation of the response is due to a decrease in ventricular contractility associated with beta adrenergic blockade. However, beta-1 blockade with propranolol did not appear to be responsible for the present observations, as evidenced by the studies in which the influence of intracardiac beta-1 blockade was compared with the influence of combined intracardiac and peripheral beta- 1 and beta- 2 
blockade. The doses of antagonists were selected so that beta1 blockade was produced to a similar extent with each agent. The volume response associated with circumflex occlusion was not significantly attenuated after beta-1 blockade but was significantly attenuated after combined beta- 1 and beta- 2 blockade. Thus, it is unlikely that attenuation of an increase in afferent vagal nerve activity with inferior wall ischemia, due to beta-1 blockade with propranolol, is responsible for the attenuation of the reflex volume increment after propranolol. Rather, the response must be attenuated because of the inhibition of a change in peripheral beta-2 receptor activity.

A decrease in peripheral beta adrenergic receptor stimulation was most likely responsible for the increase in intravascular volume with inferior wall ischemia, since a decrease in beta adrenergic receptor stimulation with propranolol was observed to increase volume in this study, whereas an increase in beta adrenergic receptor stimulation with isoproterenol is known to decrease peripheral intravascular volume $(12,13)$. A decrease in peripheral beta adrenergic stimulation with inferior wall ischemia is also consistent with the observation that circumflex occlusion is associated with a decrease in efferent sympathetic nerve activity $(14,15)$.

The efferent limb of the reflex also appeared to be mediated, in part, through changes in cholinergic receptor stimulation, since the reflex response was attenuated, but not abolished, after muscarinic receptor blockade with atropine. The attenuation of the response did not appear to be related to the change in resting intravascular volume associated with atropine administration, since atropine administration was not associated with a directionally consistent change in intravascular volume. While the doses of atropine used in the present study were of the same magnitude as those employed by other investigators to produce muscarinic receptor blockade in a preparation similar to ours (16), it is possible that partial inhibition of autonomic ganglia was also produced with these doses of atropine (17). However, since the reflex volume increment was significantly attenuated by section of the vagi at the diaphragm, one may still conclude that the reflex volume increment was mediated, in part, through changes in efferent parasympathetic receptor stimulation. It is possible that sympathetic cholinergic nerves also mediated the response, since Uvnäs (18) and others have demonstrated the presence of sympathetic cholinergic nerves that cause vasodilation in skeletal muscle when stimulated. However, the studies by these investigators suggest that sympathetic vasodilator nerve activation is not associated with depressor reflexes. In any case, even if sympathetic cholinergics are involved in the reflex volume increment, it is clear that parasympathetic cholinergic fibers are also involved. An increase in efferent parasympathetic receptor stimulation is most likely responsible for the increase in intravascular volume, since parasympathetic receptor stimulation, with acetylcholine administration or electrical stimulation of the distal vagi, is associated with an increase in peripheral intravascular volume (16).

Several possible mechanisms must be considered in order to explain the lack of a significant volume increment with LAD occlusion. First, it is possible that the absence of a significant volume increase was due to an associated reflex tendency to decrease volume, mediated outside the vagi, which counteracted a tendency to increase volume, mediated by the vagi. That this is not so is evidenced by the absence of a decrease in volume with LAD occlusion after vagectomy. Second, it is possible that the lack of a volume increase with anterior wall ischemia was due to a larger region of myocardium being made ischemic with LCX compared with LAD coronary occlusion. However, the weights of the myocardial regions made ischemic with LCX occlusion were not greater than the weights of the regions made ischemic with LAD occlusion. Also, the same amount of ventricular dysfunction was produced with LCX occlusion as with LAD occlusion, since left atrial pressure increased to the same extent with occlusion of either vessel. Third, it is possible that a volume increment was associated only with circumflex occlusion because cessation of blood flow to a major left atrial branch of the circumflex coronary artery is responsible for the response. That this is not so is evidenced by the presence of only small left atrial branches distal to the point of circumflex occlusion in less than half the atria in which atrial branches were specifically sought and by the absence of any branches distal to the point of occlusion in the remaining atria. Thus, intracardiac receptors, which are associated with a reflex increase in total intravascular volume when stimulated, are likely to be preferentially localized to the inferior surface of the heart.

The reflex volume increase is unlikely to be due to stimulation of carotid sinus, aortic, left atrial, or pulmonary venous baroreceptors for the following reasons: $(a)$ Arterial pressure decreased with circumflex occlusion; and Shoukas and Sagawa (19) have demonstrated that a decrease in mean carotid sinus pressure is associated with a reflex decrease in peripheral capacitance volume. Such a decrease in volume would attenuate the presently observed increase in volume with circumflex occlusion. (b) Furthermore, the reflex increase in capacitance volume with circumflex occlusion was still present in animals that had undergone prior sinoaortic denervation. (c) The reflex volume response was not due to the left atrial or pulmonary venous baroreceptor stimulation, initiated by the small increment in left atrial pressure (Fig. 2), since prior work has demonstrated that left atrial pressure elevation is associated with a reflex decrease in total intravascular volume (20). (d) Furthermore, the atrial pressure increased by the same amount with anterior descending occlusion as with circumflex occlusion.

The lack of a correlation between volume increment and dog weight was not unexpected. Demonstration of a possible correlation would be difficult, since 60 of the 65 dogs were of fairly uniform weight. Each animal maintained a reasonably physiologic state throughout the course of each study. The hematocrit declined by only a small amount during the experiments. Blood loss was minimal during preparation of the animals for study and during data collection. Furthermore, cardiac output and central venous pressure were maintained at constant levels. 
It is unlikely that the level of anesthesia contributed to the observed results. The appearance of a corneal reflex or spontaneous respirations, with the subsequent need for the administration of additional chloralose and urethan, occurred in only six animals. Even so, one might argue that the lack of a volume change during circumflex occlusion after atropine and propranolol administration was due to the presence of less anesthetic effect during the third period of circumflex occlusion in these animals. That this is not so is evidenced by the presence of a volume increment with circumflex occlusion during the third or fourth period of coronary occlusion in the first 10 animals.

Work by other investigators has examined the reflex autonomic influence of coronary occlusion on heart rate, ventricular contractility, and the systemic resistance vasculature. Peterson et al. (21) observed that in conscious dogs, heart rate increases with circumflex occlusion. Thames et al. (10) demonstrated that in anesthetized dogs, heart rate decreases with LCX occlusion but is unchanged with LAD occlusion. The decrease in heart rate with circumflex occlusion was abolished after vagectomy. Kaspar et al. (22) did not observe any reflex autonomic effect of circumflex occlusion on ventricular contractility. Many investigators have demonstrated a vagally mediated systemic arterial vasodilation with coronary artery occlusion $(5,7,9)$. Thames et al. (10) observed reflex arterial vasodilation in isolated, innervated gracilis muscle during LCX occlusion but not during anterior descending occlusion.

Thorén has examined the reflex influence of coronary occlusion on isolated portions of the total capacitance vasculature (7). He observed an increase in tissue blood volume in the lower extremities of cats undergoing coronary artery occlusion. The increase was abolished after cold block of the vagal nerves. However, Thorén did not delineate the efferent limb of the reflex response, nor did he examine the influence of the location of myocardial ischemia on the vascular response. Most importantly, his preparation did not allow an examination of changes in total capacitance blood volume. It is important to examine total blood volume changes, since a particular intervention may cause venoconstriction in one region of the capacitance vasculature and venodilation in another region (23). Furthermore, only changes in total peripheral capacitance blood volume can be related to changes in venous return and cardiac output. The present study was designed specifically to examine these considerations.

While the present study did not consider which regions of the total capacitance vasculature mediate the observed volume changes, other studies suggest that the splanchnic vasculature is importantly involved. These other studies have demonstrated that the decrease in peripheral intravascular volume with beta adrenergic receptor stimulation is mediated almost entirely through a decrease in transhepatic vascular resistance and a subsequent passive decrease in splanchnic blood volume (13). Furthermore, the increase in peripheral volume with parasympathetic receptor stimulation is mediated almost entirely through an increase in transhepatic vascular resistance and a subsequent increase in splanchnic blood volume (16). Since volume increments during circumflex occlusion are related to decreases in beta adrenergic receptor stimulation and increases in parasympathetic receptor stimulation, it is possible that increases in transhepatic resistance mediate the volume increments observed in the present study. In this regard, it should be noted that the reflex volume increment is abolished after bilateral section of the sympathetic (greater) splanchnic nerves. It is possible that after this removal of all sympathetic nerve stimulation to the transhepatic resistance vasculature, transhepatic resistance increases to such an extent that a subsequent increase in parasympathetic receptor stimulation is unable to cause any additional increase in transhepatic resistance and splanchnic blood volume.

Regardless of the region of the total capacitance vasculature involved, it is apparent that inferior wall myocardial ischemia is associated with an autonomically mediated increase in total blood volume in the capacitance vasculature. The afferent limb of the reflex is mediated via intracardiac receptor stimulation and the vagi, and the efferent limb, via changes in beta adrenergic and parasympathetic receptor stimulation. The reflex is not observed with anterior wall ischemia. In an animal not on venous bypass, it is likely that the observed reflex would act to decrease venous return and cardiac output.

\section{Acknowledgments}

The authors thank Francois W. Pelletier, Christopher D. Yonge, and Michael A. Ashton for their technical assistance and June B. Coons and Kelly A. Geagan for typing the manuscript.

The project was supported by National Institutes of Health New Investigator Research Award 1 R23 HL27185-01 A1 and grants from the American Heart Association of Greater Hartford, Inc. and the Duberg Cardiovascular Research Fund.

\section{References}

1. James, T. N. 1962. Arrhythmias and conduction disturbances in acute myocardial infarction. Am. Heart J. 64:416-426.

2. Thomas, M., and D. Woodgate. 1966. Effect of atropine on bradycardia and hypotension in acute myocardial infarction. Br. Heart J. 28:409-413.

3. George, M., and T. W. Greenwood. 1967. Relation between bradycardia and the site of myocardial infarction. Lancet. II:739-740.

4. Webb, S. W., A. A. J. Adgey, and J. F. Pantridge. 1972. Autonomic disturbance at onset of acute myocardial infarction. Br. Med. J. 3:8992.

5. Toubes, D. B., and M. J. Brody. 1970. Inhibition of reflex vasoconstriction after experimental coronary embolization in the dog. Circ. Res. 26:211-224.

6. Hanley, H. G., J. C. Costin, and N. S. Skinner, Jr. 1971. Differential reflex adjustments in cutaneous and muscle vascular beds during experimental coronary artery occlusion. Am. J. Cardiol. 27:513-521.

7. Thorén, P. 1973. Evidence for a depressor reflex elicited from left ventricular receptors during occlusion of one coronary artery in the cat. Acta. Physiol. Scand. 88:23-34. 
8. Peterson, D. F., and V. S. Bishop. 1974. Reflex blood pressure control during acute myocardial ischemia in the conscious dog. Circ. Res. 34:226-232.

9. Bishop, V. S., and D. F. Peterson. 1978. The circulatory influences of vagal afferents at rest and during coronary occlusion in conscious dogs. Circ. Res. 43:840-847.

10. Thames, M. D., H. S. Klopfenstein, F. M. Abboud, A. L. Mark, and J. L. Walker. 1978. Preferential distribution of inhibitory cardiac receptors with vagal afferents to the inferoposterior wall of the left ventricle activated during coronary occlusion in the dog. Circ. Res. 43:512-519.

11. Thames, M. D. 1980. Effect of $d$ - and l-propranolol on the discharge of cardiac vagal C fibers. Am. J. Physiol. 238:H465-H470.

12. Green, J. F. 1977. Mechanism of action of isoproterenol on venous return. Am. J. Physiol. 232:H152-H156.

13. Rutlen, D. L., E. N. Supple, and W. J. Powell, Jr. 1981. $\beta$ adrenergic regulation of total systemic intravascular volume in the dog. Circ. Res. 48:112-120.

14. Kezdi, P., R. K. Kordenat, and S. N. Misra. 1974. Reflex inhibitory effects of vagal afferents in experimental myocardial infarction. Am. J. Cardiol. 33: 853-860.

15. Felder, R. B., and M. D. Thames. 1979. Interaction between cardiac receptors and sinoaortic baroreceptors in the control of efferent cardiac sympathetic nerve activity during myocardial ischemia in dogs. Circ. Res. 45:728-736.

16. Supple, E. W., and W. J. Powell, Jr. 1981. Effect of acetylcholine on vascular capacity in the dog. J. Clin. Invest. 68:64-74.

17. Taylor, P. 1980. Ganglionic stimulating and blocking agents. In The Pharmacological Basis of Therapeutics. A. G. Gilman, L. S. Goodman, and A. Gilman, editors. Macmillan, Inc. New York. 6th ed. 84.

18. Uvnäs, B. 1954. Sympathetic vasodilator outflow. Physiol. Rev. 34:608-618.

19. Shoukas, A. A., and K. Sagawa. 1973. Control of total systemic vascular capacity by the carotid sinus baroreceptor reflex. Circ. Res. 33:22-33.

20. Rutlen, D. L. 1981. Reflex effects of left atrial pressure elevation on total intravascular volume. Am. J. Physiol. 241:H760-H765.

21. Peterson, D. F., R. L. Kaspar, and V. S. Bishop. 1973. Reflex tachycardia due to temporary coronary occlusion in the conscious dog. Circ. Res. 32:652-659.

22. Kaspar, R. L., G. E. Barnes, D. F. Peterson, and V. S. Bishop. 1975. Specificity of autonomic influences on cardiac responses during myocardial ischemia. J. Appl. Physiol. 33:485-490.

23. Shepherd, J. T., and P. M. Vanhoutte. 1975. Veins and Their Control. W. B. Saunders Company Ltd., London. 105-106. 